\title{
Waste Management Risks and Opportunities Identification in Malaysia TVET Institution
}

\author{
Rodzidah Mohd Rodzi, Zulkifli Mohd Nopiah’ Noor Ezlin Ahmad Basri
}

\begin{abstract}
Rising amount of generated waste is an increasing concern for the future generation potentially at risk. The purpose of this research was to identify the risks and opportunities associated with waste management practices in Malaysia TVET Institution as per requirements under ISO 9001:2015 Clause 6.1. Using Risk-Based Thinking (RBT), Preliminary Risk Assessment (PRA) and SWOT Analysis, this research analyzed the hazardous events of managing Municipal Solid Waste (MSW) and Hazardous Waste (HW). The risks associated with MSW divided into 5 categories; human damage, climate pollution, soil, air and water contamination. Whereas, HW risks US EPA characteristics were ignitable, corrosive, reactive and toxic. The findings presented in Risk Matrix (High, Medium or Low level), revealed that the top ranking risk for MSW was fatal diseases and misplacing SW4 for HW. The research recommended more ground works in RBT application as it involves thorough look at workplace to establish a most-to-least-critical importance ranking.

Keywords : Hazardous Waste, ISO 9001:2015, Municipal Solid Waste, Risk-Based Thinking
\end{abstract}

\section{INTRODUCTION}

Poor garbage waste management is a sore to the eye and not only affects the nature aesthetic value but economy as well. Improper waste dumping comes with really harmful effects, some of which may be felt earlier while others take time. In 2017, Malaysian Government launched Green-Blue Packaging (GB). The aim of this initiative was to ensure that polythene food containers are replaced, having been observed to be non-biodegradable. With toxic chemicals associated with these containers, the initiative strived to minimize environmental pollution (that had come in the form of sewerage and drainage system choking) [2]. In order to attain the objectives of the National Waste Management strategies, the cornerstone of a quality organization is an effective Quality Management System (QMS). ISO 9001 is the most widely used and recognized standard for QMS internationally [4].

In 2017, there came the QMS, which was an alternative version to the Malaysian Standard MS ISO 9001:2015. Governed by the Department of Standards Malaysia (DSM), this version replaced ISO 9001:2008, a former version.

Revised Manuscript Received on July 22, 2019

Rodzidah Mohd Rodzi1, Zulkifli Mohd Nopiah, Noor Ezlin Ahmad Basri

Centre of Engineering Education Research, Faculty of Engineering \& Built Environment, The National University of Malaysia, 43600 UKM Bangi, Selangor, Malaysia.

Department of Civil \& Structural Engineering, Faculty of Engineering \& Built Environment, The National University of Malaysia, 43600 UKM Bangi, Selangor, Malaysia.
Regarding the process of organizing accreditation and certification, the Standard and Industrial Research Institute of Malaysia (SIRIM) plays an important and leading role towards the implementation of these procedures. Notably, QSM called for the implementation of Clause 6.1, which requires that Risk-Based Thinking (RBT) is adopted. Particularly, the clause provides room for the implementation of several actions through which opportunities and risks are addressed. Also, the actions are expected to be proportionate to the impact that they are likely to have on product and service conformity. Poor garbage waste management is a sore to the eye and not only affects the nature aesthetic value but economy as well. Improper waste dumping comes with really harmful effects, some of which may be felt earlier while others take time. In 2017, Malaysian Government launched Green-Blue Packaging (GB). The aim of this initiative was to ensure that polythene food containers are replaced, having been observed to be non-biodegradable. With toxic chemicals associated with these containers, the initiative strived to minimize environmental pollution (that had come in the form of sewerage and drainage system choking) [2]. In order to attain the objectives of the National Waste Management strategies, the cornerstone of a quality organization is an effective Quality Management System (QMS). ISO 9001 is the most widely used and recognized standard for QMS internationally [4].

Imperative to highlight is that formal methods through which risk management systems could be documented (or implemented) are not accounted in the ISO 9001:2015 standard [1].

Risk is uncertainty that matters and may impact any of product or service objectives. This impact can be positive (opportunities) and negative (threats). The Chinese word, for risk is wēijī 危机, signifying "danger" and "opportunity" [3]. Referring to ISO 9001:2015 Clause 6.1, the new requirement RBT requires organizations to ensure that opportunities and risks that are likely to pose negative or positive effects on management system performance and operation are indentified. Technically, the forecasting by practicing risk management: identification, assessment, prioritization and planning precautionary actions to mitigating or avoiding the risks

The main problem faced by organizations was ISO 9001:2015 does not prescribe a risk methodology which means they are free to adopt their own approach. The intent was that each organization assessing their own unique risks and opportunities. In other words, "is to do whatever is 
right for your business". It is also notable that there exist different methodologies but for the case of ISO 9001:2015, formal risk management is not necessary; neither does this methodology emphasize specific approaches for achieving risk identification and the documentation of the results. It is up to each organization to determine the extent of documentation needed to provide objective evidence of the RBT application. Moreover, the multiplicity of sources and methods makes it difficult to compile one compact and efficient preventive action process [7].

\section{OBJECTIVE}

Since many concerns have been raised about the challenges of no standardization in new revised QMS, this research applying RBT approach as required in MS ISO 9001:2015. The objective in this research was to identify the risks and opportunities associated with waste management practices in the Malaysia TVET Institution.

\section{METHODOLOGY}

Research background: Notably, this study is limited in a certain way. In particular, the aspect of Quality Management Team (QMT) may be interacted by following the procedure of government protocol and not the ISO business practice guidelines. Assumptions were the QMT had high level of environmentally awareness and practicing proper waste management on daily basis. The interest of these parties is seen to lie in idea generation but the enforcement of the perceived orders remains questionable and relatively wanting. This study's research context was a TVET organization. The choice of this institution was based on training workshops that it holds relative to industrial skills; especially on subjects such as hazardous waste and municipal solid waste disposal. Indeed, the institution, through these workshops, gains exposure to different subjects on risks such as leachate, gaseous, bugs, infections, toxic effects and injuries from improper waste management.

Research Location: Imperatively to note is that the specific area that was chosen to gain data entailed a public vocational institute. Specifically, information was gained from a public TVET institution. The Ministry of Human Resources Malaysia (MOHR) was in charge of this institution. Founded in 1964, the organization rests on 13.7 acres of land. Geographically, it lies $3^{\circ} 05^{\prime} 33.1^{\prime \prime} \mathrm{N}, 101^{\circ} 41^{\prime} 13.5^{\prime \prime} \mathrm{E}$ in Kuala Lumpur's Kuchai Lama area (see Figure 1). With 577 students and a staff of 182 individuals, 12 courses are offered in the institution (by 2018) [5].

\section{CONCLUSION}

Rising amount of generated waste is an increasing concern for the future generation potentially at risk. The purpose of this research was to identify the risks and opportunities associated with waste management practices in Malaysia TVET Institution as per requirements under ISO 9001:2015
Clause 6.1. Using Risk-Based Thinking (RBT), Preliminary Risk Assessment (PRA) and SWOT Analysis, this research analyzed the hazardous events of managing Municipal Solid Waste (MSW) and Hazardous Waste (HW). The risks associated with MSW divided into 5 categories; human damage, climate pollution, soil, air and water contamination. Whereas, HW risks US EPA characteristics were ignitable, corrosive, reactive and toxic. The findings presented in Risk Matrix (High, Medium or Low level), revealed that the top ranking risk for MSW was fatal diseases and misplacing SW4 for HW. The research recommended more ground works in RBT application as it involves thorough look at workplace to establish a most-to-least-critical importance ranking.

\section{REFERENCES}

1. Aseel M. Aljeboree, A.N.A., Adsorption of Pharmaceuticals as emerging contaminants from aqueous solutions on to friendly surfaces such as activated carbon: A review J. Pharm. Sci. \& Res. , 2018. 10(9): p. 2252-2257

2. J.L. Tambosi, L.Y.Y., H.J.J.R. de Fátima Peralta Muniz Moreira, H.F. Schröder, Recent research data on the removal of pharmaceuticals from sewage treatment plants (STP). Quim Nova, 2010. 33: p. 411-420.

3. Aseel Musthaq Aljeboree, A.N.A., Colorimetric Determination of phenylephrine hydrochloride drug Using 4-Aminoantipyrine: Stability and higher sensitivity J. Pharm. Sci. \& Res., 2018 10(7): p. 1774-1779

4. Jones, O.A., J.N. Lester, and N. Voulvoulis, Pharmaceuticals: a threat to drinking water? Trends in Biotechnology, 2005. 23(4): p. 163-167.

5. Aseel M. Aljeboree, A.S.A., Removal of Pharmaceutical (Paracetamol) by using CNT/ TiO2 Nanoparticles. Journal of Global Pharma Technology, 2019. 11 ( 01 ): p. 199-205.

6. Stackelberg, P.E., et al., Persistence of pharmaceutical compounds and other organic wastewater contaminants in a conventional drinking-water-treatment plant. Science of The Total Environment, 2004 329(1): p. 99-113.

7. A.F. ALKAIM1, A.M.A.N.A.A., S.J. BAQIR2 , F.H. HUSSEIN and A.J LILO2, Effect of $\mathrm{pH}$ on Adsorption and Photocatalytic Degradation Efficiency of Different Catalysts on Removal of Methylene Blu.

8. Aljeboree, A.M., A. N. Alshirifi, et al. , "Kinetics and equilibrium study for the adsorption of textile dyes on coconut shell activated carbon.Arabian Journal ofChemistry, 2012. 10: p. S3381-S3393.

9. Alkaim AF, A.A., Alrazaq NA, Baqir S.J, Hussein F.H and Lilo AJ, Effect of $\mathrm{pH}$ on Adsorption and Photocatalytic Degradation Efficiency of Different Catalysts on Removal of Methylene Blue. Asian Journal of Chemistry, , 2014. 24(26): p. 8445-8448.

10. AM, A., Adsorption of crystal violet dye by Fugas Sawdust from aqueous solution. International Journal of ChemTech Research. 9(3): p. 412-423.

11. Abdulrazzak, F.H., Enhance photocatalytic Activity of $\mathrm{TiO} 2$ by Carbon Nanotubes.International Journal of ChemTech Research, 2016. 9(3): p 431-443

12. AF Alkaim, T.K., FH Hussein, R Dillert, DW Bahnemann, Solvent-free hydrothermal synthesis of anatase $\mathrm{TiO} 2$ nanoparticles with enhanced photocatalytic hydrogen production activity. Applied Catalysis A: General 2013. 466 p. 32-37.

13. Tarek A. Kandiel, L.R., Ayad Alkaim and Detlef Bahnemann, Brookite versus anatase $\mathrm{TiO} 2$ photocatalysts: phase transformations and photocatalytic activities $\dagger$. Photochemical \& Photobiological Sciences, 2013. 12: p. 602.

14. M. R. Hoffmann, S.T.M., W. Y. Choi and, E.a.o.s. D. W. Bahnemann, and C.R. photocatalysis, 1995, 95, 69-96., Environmental applications of semiconductor photocatalysis Chem. Rev, 1995. 95: p. 69-96.

15. K. Hashimoto, H.I.a.A.F., TiO2 photocatalysis:a historical overview and future prospects. J. Appl.Phys., 2005. 44: p. 8269-8285.

16. M. P. Finnegan, H.Z.Z.a.J.F.B., Phase stability and transformation in titania nanoparticles in aqueous solutions dominated by surface energy. J. Phys.Chem. C 2007. 111.: p. 1962-1968.

17. T. A. Kandiel, R.D.a.D.B., Titanium dioxide nanoparticles and nanostructures. Curr. Inorg.Chem., 2012. 2: p. 94-114.

18. Banfield, H.Z.Z.a.J.F., Understanding polymorphic phase transformation behavior during growth of nanocrystalline aggregates: insights from $\mathrm{TiO} 2$. J. Phys. Chem. B,, 2000. 104: p. 3481-3487.

19. HUSSEIN PHOTOCATALYTIC 
DEGRADATION OF EDTA BY USING TiO2 SUSPENSION.Int. J. Chem. Sci., 2012. 10(1): p. 586-598.

20. H. Wang, C. Xie, W. Zhang, S. Cai, Z. Yang, and Y. Gui, Comparison of dye degradation efficiency using $\mathrm{ZnO}$ powders with various size scales. J. Hazard Mater., 2007. 141(3): p. 645-652.

21. J. Kaur, and S. Singhal, Heterogeneous photocatalytic degradation of rose bengal: Effectof operational parameters. Physica B, 2014. 450: p. 49-53.

22. M. S. Mashkour, A. F. Alkaim, L. M. Ahmed, and F. H. Hussein, Zinc oxide assisted photocatalytic decolorization of reactive red 2 dye. Int. J. Chem. Sc., 2011. 9(3): p. 969-979.

23. M., G.M.S.T.O.-C.A.M.F.P.E.M.P.P.M.S.Q., J., Chemosphere 1999. 39: p. 781.

24. G., C.F.X.Y.Z.J.L., Chemosphere 2000. 44: p. 1159.

25. I., P.I.A., J. Chem. Technol. Biotechnol., 1999. 74 p. 349.

26. H., H.L.E.P.A.H.M.K.E.E.C.G.J., Appl. Catal. B: Environ., 2002. 39 p. 75.

27. T. Sauer, G. C. Neto, H.J. José, and R.F. Moreira, Kinetics of photocatalytic degradation of reactive dyes in a $\mathrm{TiO} 2$ slurry reactor. J. Photochem. Photobiol. A, 2002. 149: p. 147-154.

28. Aseel M. Aljeboree, H.Y.A.-G., Mohammed H. Said and Ayad F. Alkaim, THE EFFECT OF DIFFERENT PARAMETERS ON THE REMOVAL OF VITAMIN B12 DRUG (AS A MODEL BIOCHEMICAL POLLUTANTS) BY AC/ CLAY.Biochem. Cell. Arch., 2019. 19(1): p. 000-000.

29. Miao J, J.Z., Lu HB, Habibi D and Zhang L, , Heterogeneous photocatalytic degradation of mordant black 11 with $\mathrm{ZnO}$ nanoparticles under UV-Vis light. Journal of the Taiwan Institute of Chemical Engineers, 2014. 45: p. 1636-1641

30. Aseel M. Aljeboree, A.F.A., Ali loay2 , hanadi m algburi, Photocatalytic Degradation of Textile Dye Cristal Violet Wastewater using Zinc Oxide as a Model of Pharmaceutical Threat Reductions. Journal of Global Pharma Technology, 2019. 11(3): p. 138-143. 